\title{
Results of Magnetic Measurements and Field Integral Compensation for the Elliptical Multipole Wiggler

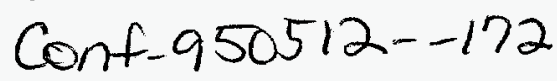

\author{
D. Frachon, P. M. Ivanov, E. A. Medvedko, I. Vasserman, O. Despe, Y. G. Kang \\ APS, Argonne National Laboratory, Argonne, IL 60439
}

\section{ABSTRACT}

A prototype of the Elliptical Multipole Wiggler (EMW) [1] has been assembled, tested and tuned at the APS. This prototype has a period of $160 \mathrm{~mm}$ with 7 poles for the hybrid structure and 10 poles for the electromagnet part of the EMW. The hybrid structure of the EMW produces a vertical magnetic field of $0.83 \mathrm{~T}$ with $\mathrm{K}_{\mathrm{y}}=12$ for a gap of $27 \mathrm{~mm}$, and the electromagnetic structure provides a horizontal field change up to $100 \mathrm{~Hz}$ with a maximum field of $0.12 \mathrm{~T}\left(\mathrm{I}=0.6 \mathrm{kA}, \mathrm{K}_{\mathrm{X}}=\right.$ 1.6). The current pulse has a trapezium-type shape with a switching time to change the current polarity of about $2 \mathrm{~ms}$. The measurements and tuning were done for direct current (DC) mode and alternating current (AC) mode. Fine adjustment during the test at the NSLS X-ray ring using the BPMs and active correction system allowed to achieve about 1 $\mu \mathrm{m}$ of beam distortion. It corresponds to the peak-to-peak variations during the time less than $\pm 0.5 \mathrm{G}-\mathrm{cm}$ and $\pm 100 \mathrm{G}-$ $\mathrm{cm}^{2}$ of the first and second horizontal field integrals respectively.

\section{INTRODUCTION}

Two different correction systems were used to adjust the first and the second field integrals dependence on time.. A passive correction system includes manually adjustable gaps for the end poles. The adjustment of the first horizontal field integral was performed by moving the gap of each end pole in the opposite direction. The adjustment of the second horizontal field integral was performed by moving the gap of each end pole in the same direction without distortion of the first field integral due to the antisymmetric configuration of the device. The active correction system is based on the use of a set of two trim magnets mounted on each end of the device. The magnet coils are fed by a power supply with an arbitrary function generator [2].

\section{MAGNETIC MEASUREMENT TECHNIQUE}

The conventional Hall probe technique was used for measurements of the magnetic field distribution in the longitudinal direction. The rotating coil magnetic measurement technique was used for field integral measurements. Actually the rotating mode was necessary only for the DC mode. For the AC mode, the FAST 16-1 ADC board was used with a sampling time of $0.1 \mathrm{~ms}$ for a frequency of $100 \mathrm{~Hz}$. The CTM05 board was installed on the PC bus and used to generate pulses to define the frequency of the power supply and to trigger the FAST 16-1 ADC board to synchronize measurements. The integration of the signal from the coil provides the flux dependence on time through the coil. The most important part of the EMW measurements is the field integral dependence of electromagnetic structure on time for the AC mode . Measurements of the second field integral by the usually applied technique of measuring the field map are very time consuming. The reason is that such measurements are based on the step-by-step motion of magnetic sensors along the main axis of the device and on time-dependent measurements at each point. That is why a novel technique using a twisted long coil was used for fast and precise magnetic measurements of second field integrals [3].

\section{MAGNETIC FIELD MEASUREMENTS}

The results of Hall probe measurements of the vertical and horizontal field distributions are shown in Fig. 1.
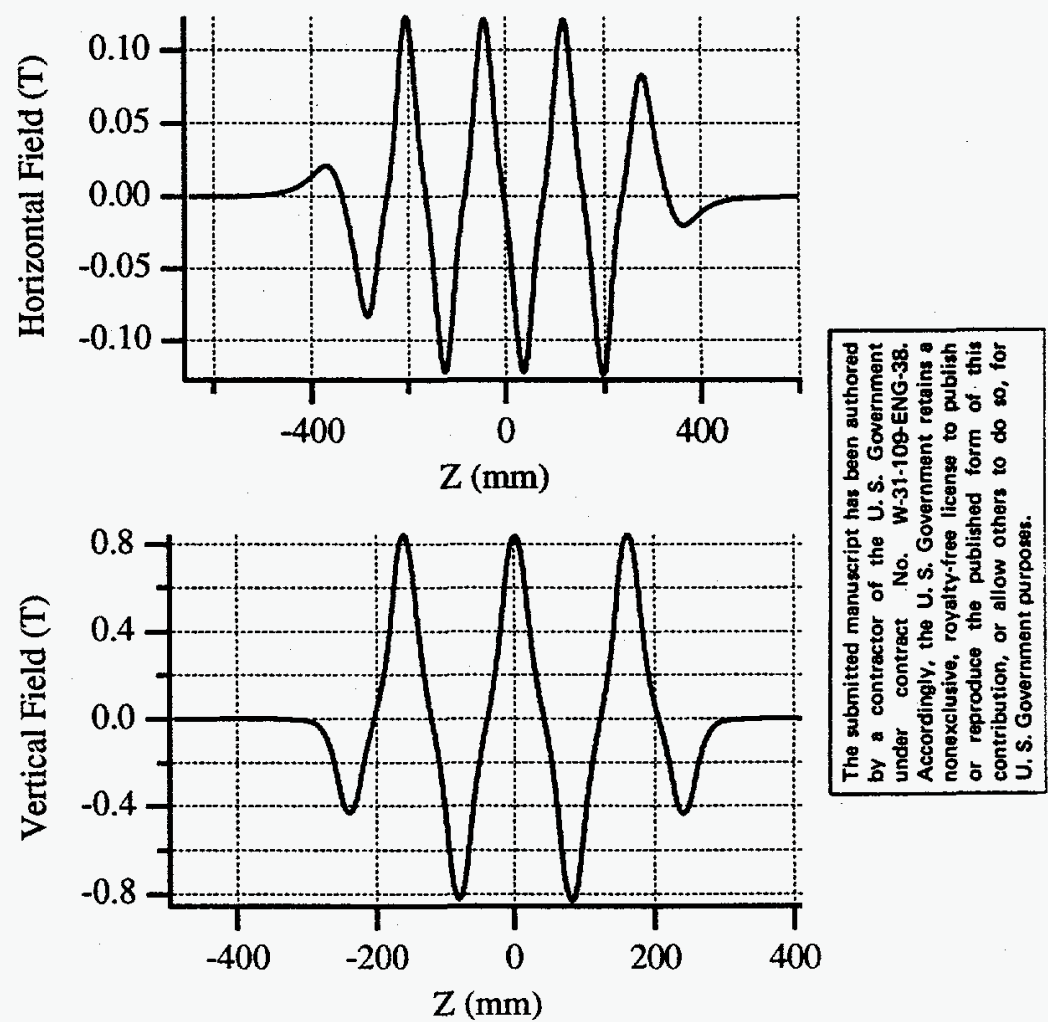

Fig. 1. Horizontal and Vertical Field vs. Z

It is important that we have very tight requirements for the average horizontal first field integral at regular parts of the device, which is usually not important. Due to the AC operational mode, the averaged angle of trajectory changes its sign according to current polarity. This results in the requirement that this angle be much less than the particle angle spread of the beam, that is $2 * 10^{-4}$, in order not to distort the radiation quality of the device. Thus the strength of the field of the last and next-to-last end poles was chosen to make the trajectory as close to ideal as possible. The result of 


\section{DISCLAIMER}

This report was prepared as an account of work sponsored by an agency of the United States Government. Neither the United States Government nor any agency thereof, nor any of their employees, makes any warranty, express or implied, or assumes any legal liability or responsibility for the accuracy, completeness, or usefulness of any information, apparatus, product, or process disclosed, or represents that its use would not infringe privately owned rights. Reference herein to any specific commercial product, process, or service by trade name, trademark, manufacturer, or otherwise does not necessarily constitute or imply its endorsement, recommendation, or favoring by the United States Government or any agency thereof. The views and opinions of authors expressed herein do not necessarily state or reflect those of the United States Government or any agency thereof. 


\section{DISCLAIMER}

Portions of this document may be illegible in electronic image products. Images are produced from the best available original document. 
the calculation of the second horizontal field integral from the Hall probe data is shown in Fig. 2.

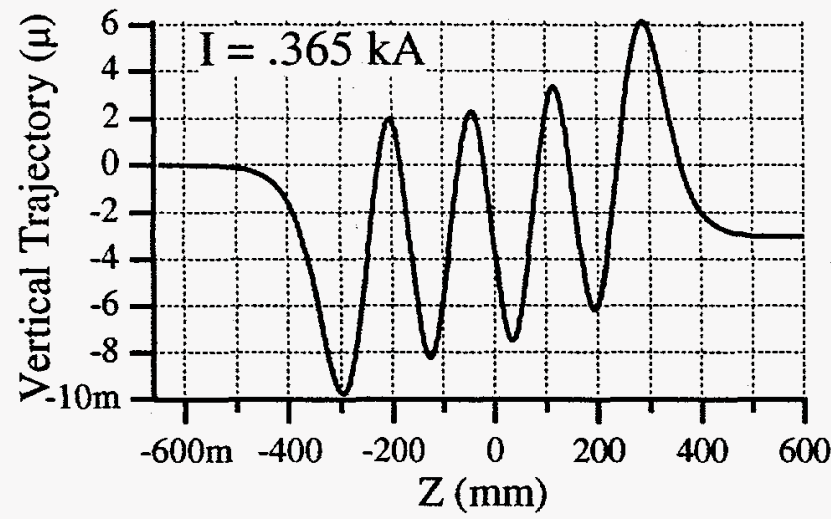

Fig. 2. Vertical Trajectory in the DC mode

\section{FIRST FIELD INTEGRAL MEASUREMENTS}

A conventional long coil with parallel wires was used for first field integral measurements. For measurements of hybrid structure and of the electromagnet in the DC mode, coil rotating at $360^{\circ}$ was used. Actually these measurements were complementary to the main set of measurements that was done in the AC mode without rotating the coil. The results of the $\mathrm{AC}$ first horizontal field integral measurements are shown in Fig. 3 with active correction on and off. The first horizontal field integral change during the cycle is less than 10 G-cm without active correction and less than $1 \mathrm{G}-\mathrm{cm}$ with active correction switched on.

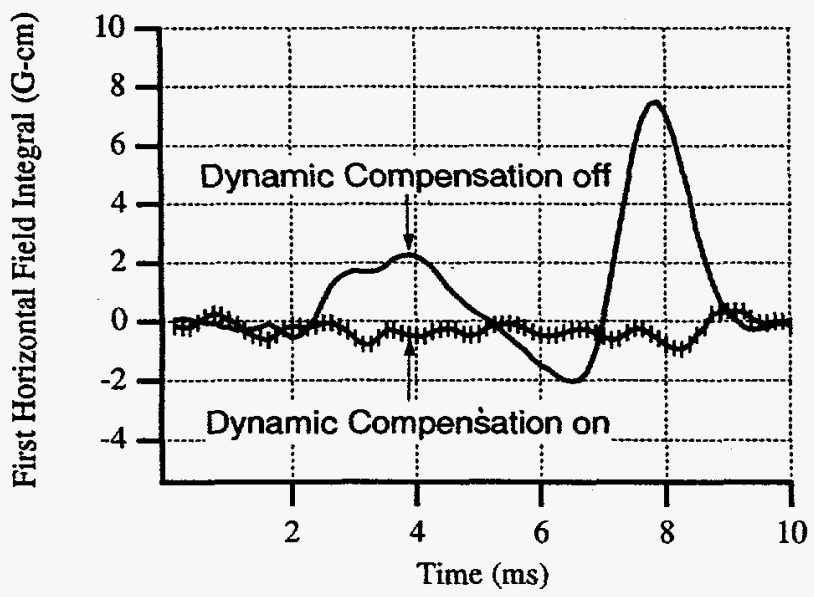

Fig. 3. First Horizontal Field Integral vs. Time. $\mathrm{f}=100 \mathrm{~Hz}$

The time dependence of the field integrals can be divided into two parts:

1. DC part. This part is a result of different signs of the current and can be easily adjusted by choosing the proper gaps for the end poles. This part manifests mainly for low frequencies (less than $10 \mathrm{~Hz}$ ).

2. AC part. The length of this part is much longer than the switching time (2 ms) and is about $50 \mathrm{~ms}$. It is due to an eddy-current-produced delay of the field penetrating to the air space. Small differences in the design produce different delay times for different parts of the device and result in field integral dependence on time. The only way to correct for this is to apply an active system fed by a special power supply with an arbitrary function generator. Both parts of the first field integral time dependence can be easily seen at a frequency of $1 \mathrm{~Hz}$ (Fig. 4) without dynamic correction. Only the DC part was adjusted here by means of a passive end-correction system.

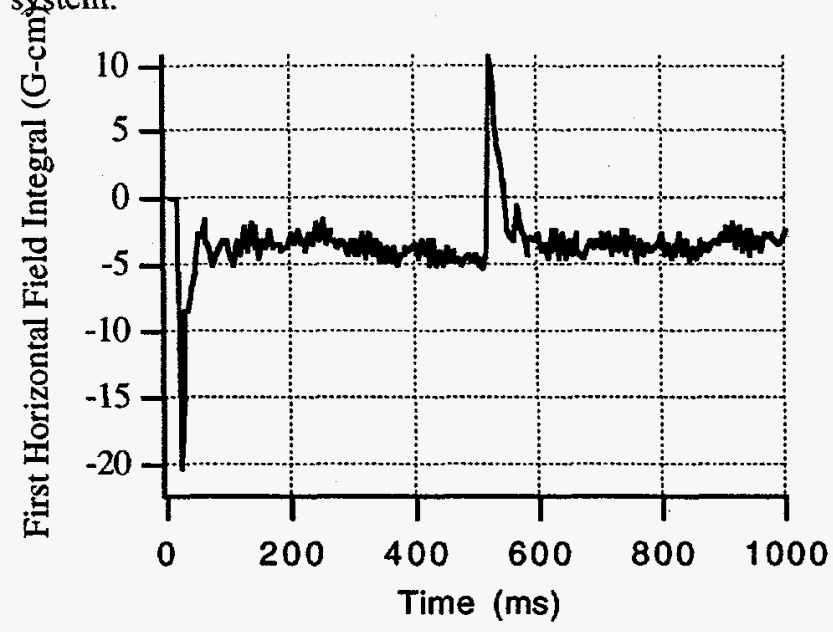

Fig. 4. First Horizontal Field Integral vs. Time. $\mathrm{f}=1 \mathrm{~Hz}$

The dependence of the first and second vertical field integrals on time exists due to the saturation effect of the electromagnetic field on hybrid structure. There was no active correction system for the vertical direction at the time of the measurements, and the change in the field integral therefore is bigger than that for the horizontal direction. The first vertical field integral change during the cycle is less than $45 \mathrm{G}-\mathrm{cm}$. The results of the measurements of the AC first vertical field integral are shown in Fig. 5

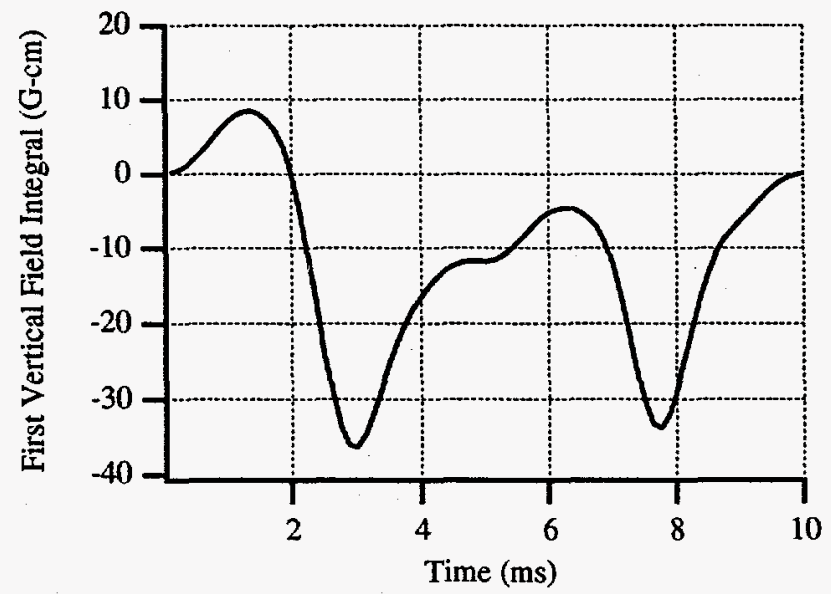

Fig. 5. First Vertical Field Integral vs. Time. $f=100 \mathrm{~Hz}$

\section{SECOND FIELD INTEGRAL MEASUREMENTS}

Coil twisted by $180^{\circ}$ was used to obtain the second field integral from these measurements. At such a configuration, the expression for the second field integral dependence on the measured magnetic flux and the first field integral is [3]:

$I_{2}(L)=-\frac{\Phi}{\Theta}+L \cdot I_{1}(L), \quad$ where: $I_{1}(L)$ and $I_{2}(L)$ are the 
first and second field integrals, respectively; $\Phi$ is the magnetic flux through the coil; $L$ is the half length of the coil; and $\Theta$ is the crossing angle of the coil. This expression becomes especially simple and allows one to achieve the most reliable and precise results in the case in which the first field integral is equal to zero.

The results of second field integral measurements are shown in Fig. 5 at a frequency of $100 \mathrm{~Hz}$. Change in the second horizontal field integral during the cycle is less than $4000 \mathrm{G}-$ $\mathrm{cm}^{2}$ without active correction and about $1000 \mathrm{G}-\mathrm{cm}^{2}$ with active correction switched on. Change in the second vertical field integral change during the cycle is less than $3000 \mathrm{G}-\mathrm{cm}^{2}$.
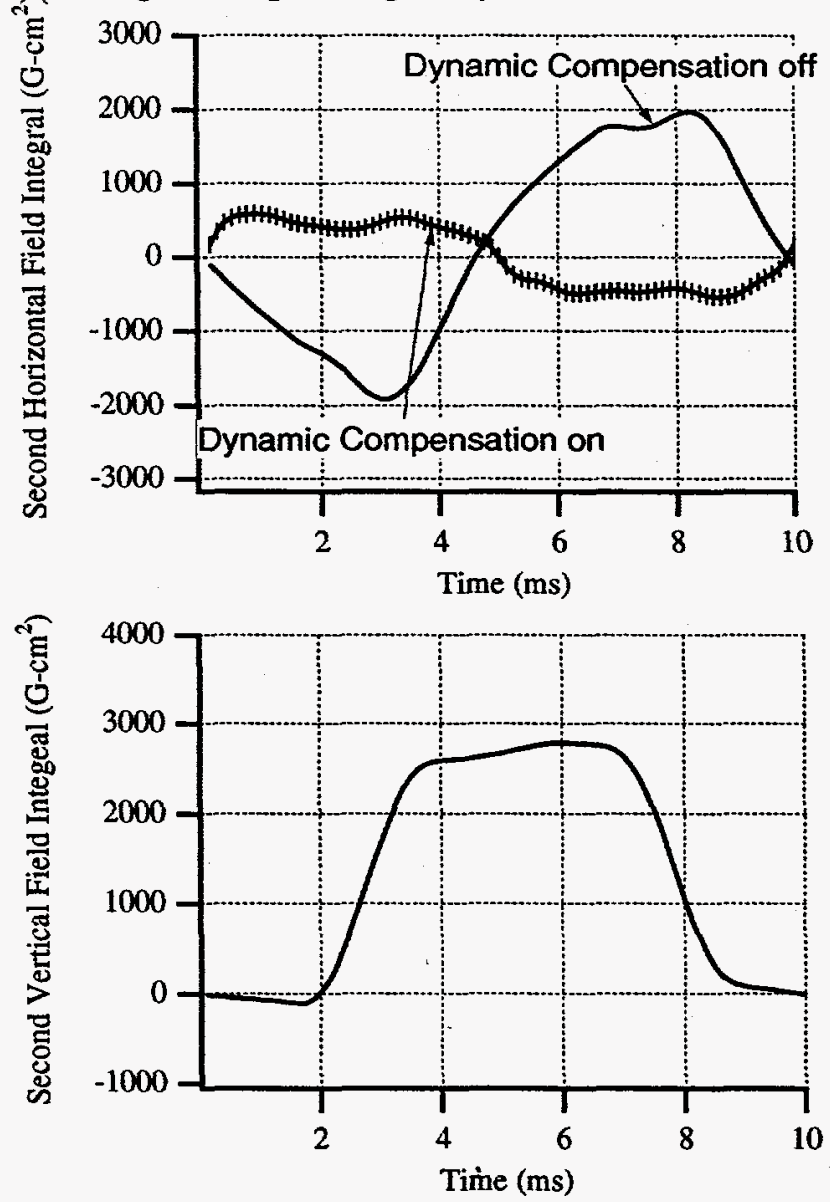

Fig. 6. Second Horizontal and Vertical Field Integral Dependence on Time. $f=100 \mathrm{~Hz}$

\section{INTEGRATED MULTIPOLE COMPONENTS}

There were no special requirements for multipole components, but this question is rather important from the point of view of beam life time and beam dimensions in the storage ring. So a set of measurements was performed in order to obtain the dependence of the first field integral on the horizontal position (X) for both the AC mode and the DC mode. The DC mode originates mostly from the hybrid structure, and the $\mathrm{AC}$ mode originates from the electromagnetic part and time-dependent part of the hybrid structure due to a saturation effect induced by the electromagnet. The results of measurements of the DC mode obtained from the rotating coil measurements are shown in Table 1.

Table 1. Integrated Multipole Components at DC mode

Skew components

\begin{tabular}{|c|c|c|}
\hline Ouadrupole (G) & Sextupole $(\mathrm{G} / \mathrm{cm})$ & Octupole $\left(\mathrm{G} / \mathrm{cm}^{2}\right)$ \\
\hline 183. & 29. & 29.4 \\
\hline
\end{tabular}

Normal Components

\begin{tabular}{|c|c|c|}
\hline Ouadrupole (G) & Sextupole $(\mathrm{G} / \mathrm{cm})$ & Octupole $\left(\mathrm{G} / \mathrm{cm}^{2}\right)$ \\
\hline 48.3 & -383. & 0.23 \\
\hline
\end{tabular}

The results of the time-dependent part of the multipole components are shown in Table 2. For each $\mathrm{X}$ position, the dependence of the first field integral on time was obtained and the RMS value was calculated. The results, shown in Table 2, correspond to dependence of these RMS values on X.

Table 2. Integrated Multipole Components in the AC mode

Skew Components

\begin{tabular}{|c|c|c|}
\hline Ouadrupole $(\mathrm{G})$ & Sextupole $(\mathrm{G} / \mathrm{cm})$ & Octupole $\left(\mathrm{G} / \mathrm{cm}^{2}\right)$ \\
\hline-1.38 & 11.6 & -13.8 \\
\hline
\end{tabular}

Normal Components

\begin{tabular}{|c|c|c|}
\hline Ouadrupole (G) & Sextupole $(\mathrm{G} / \mathrm{cm})$ & Octupole $\left(\mathrm{G} / \mathrm{cm}^{2}\right)$ \\
\hline 0.13 & 4.39 & 0.91 \\
\hline
\end{tabular}

\section{CONCLUSION}

The first tests of the EMW at the NSLS X-ray ring with frequencies of $2 \mathrm{~Hz}$ and $100 \mathrm{~Hz}$ were successful and showed rather good performance of the device [1]. Further improvements in vertical magnetic field are possible with the help of an additional set of trim magnets. This system is under construction now and will be incorporated into the EMW later.

\section{ACKNOWLEDGMENTS}

Work performed under contracts W-31-109-ENG-38 and DEAC-02-76-CH-00016 of the U.S. Department of Energy.

\section{REFERENCES}

1. E. Gluskin et al. "The Elliptical Multipole Wiggler Project," This conference

2. O. D. Despe, "Arbitrary Function Generator for APS Injector Synchrotron Correction Magnets," PAC-1991, SanFrancisco

3. D. Frachon, I. Vasserman, P. M. Ivanov, E. A. Medvedko, E. Gluskin, N. A. Vinokurov. "Magnetic Measurements of the Elliptical Multipole Wiggler Prototype," ANL/APS/TB22, March 1995 